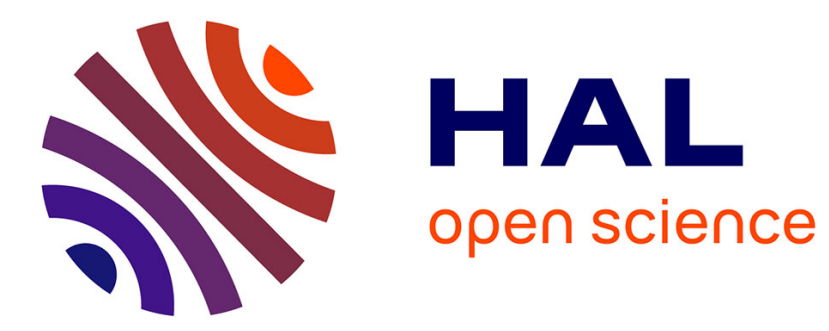

\title{
Evaluation of risk factors for retinal damage due to chloroquine and hydroxychloroquine
}

\author{
Richard Bergholz, Jan Schroeter, Klaus Ruether
}

\section{To cite this version:}

Richard Bergholz, Jan Schroeter, Klaus Ruether. Evaluation of risk factors for retinal damage due to chloroquine and hydroxychloroquine. British Journal of Ophthalmology, 2010, 94 (12), pp.1637. 10.1136/bjo.2009.174458. hal-00585174

\section{HAL Id: hal-00585174 https://hal.science/hal-00585174}

Submitted on 12 Apr 2011

HAL is a multi-disciplinary open access archive for the deposit and dissemination of scientific research documents, whether they are published or not. The documents may come from teaching and research institutions in France or abroad, or from public or private research centers.
L'archive ouverte pluridisciplinaire HAL, est destinée au dépôt et à la diffusion de documents scientifiques de niveau recherche, publiés ou non, émanant des établissements d'enseignement et de recherche français ou étrangers, des laboratoires publics ou privés. 


\title{
Evaluation of risk factors for retinal damage due to chloroquine and hydroxychloroquine
}

\author{
Bergholz R, Schroeter J, Rüther K \\ Department of Ophthalmology, Charité - Universitätsmedizin Berlin, Campus \\ Virchow-Klinikum
}

Background/ Aims: To evaluate risk factors for retinal damage due to the intake of chloroquine and hydroxychloroquine.

Methods: In a retrospective chart review, patients receiving or having received one of the drugs were classified as affected by maculopathy or retinopathy or as not affected on the basis of the documented findings. Uncertain cases were excluded. The risk factors as postulated by the American Academy of Ophthalmology (AAO) and additional factors like diagnosis of underlying disease, total dose, nicotine abuse and the sum of the AAO risk factors were compared between both groups.

Results: 51 patients with a history of or ongoing treatment with chloroquine (23 individuals) or hydroxychloroquine (28 individuals) were included. Most of the postulated risk factors were expectedly elevated in the affected group. Significant differences applied to age, duration of intake and the sum of AAO risk factors. Surprisingly, positive smoking history was more frequent in the not affected. The toxic threshold of the daily chloroquine dose was exceeded by most of the patients.

Conclusions: Age and the duration of intake are major risk factors. Smoking seems to be negligible. The sum of AAO risk factors can give an estimation of the individual risk profile. Individual and weight-adapted dosing is especially essential for chloroquine. 


\section{Introduction}

Chloroquine and hydroxychloroquine are effective and safe drugs for the treatment of autoimmune diseases. Nevertheless, they bear the risk of irreversibly damaging the retina. The incidence of chloroquine maculopathy supposedly lies between 1 and 6 $\%$, of hydroxychloroquine maculopathy below $1 \%$. According to a report by the American Academy of Ophthalmology (AAO) the following risk factors are assumed to play key roles in the development of the disease: ${ }^{2}$

- High daily dosage per kilogram body weight $(>6.5 \mathrm{mg} / \mathrm{kg}$ of hydroxychloroquine and $>3 \mathrm{mg} / \mathrm{kg}$ of chloroquine)

- Long duration of intake ( $>5$ years)

- High body fat level

- Liver or kidney disease

- Concomitant retinal disease

- Age $>60$ years

Ophtalmologic screening intervals should be based on the risk profile. Currently, annual examinations are recommended for any patient who fulfills at least one of the above mentioned criteria. Screening intervals of low risk patients depend on their age and range from once in ten years to annually. However, there are cases of retinal damage even in low risk patients. On the other hand some high-risk patients are completely unaffected. ${ }^{3}$ Furthermore, a recently published case from our department confirmed the variability of the retinotoxic cumulative dosage. ${ }^{4}$

In this retrospective study we reevaluate assumed major risk factors in a patient sample of our department.

\section{Methods}

We reviewed the files of all patients who presented at our department between 2002 and 2008 for evaluation of retinal damage due to chloroquine or hydroxychloroquine. Examinations were performed by the authors RK and SJ. Basically, the individuals were classified as affected or not affected according to the documented examinations and a classification scheme:

\section{Affected:}

- Fulfilment of the following criterion:

- Reproducible bilateral paracentral amplitude decrease in the multifocal electroretinogram (mfERG) and exclusion of other causes like age related macular degeneration (ARM)

- PLUS fulfilment of at least one of the following criteria:

- Reduced best corrected visual acuity (only if all other possible causes were ruled out)

- Typical fundus morphology (bull's eye maculopathy or peripheral retinochoroidal atrophy)

- Reproducible central or paracentral scotoma in the automated threshold perimetry 
- In case of an equivocal mfERG: fulfilment of at least two of the remaining criteria.

Unequivocal paracentral amplitude decrease in the multifocal ERG was a necessary criterion for classification as affected. Only in case of an equivocal mfERG fulfilment of at least two of the remaining criteria was sufficient for classification as affected. Uncertain cases were excluded from the study. All other patients were classified as not affected.

If a patient presented more than once in our department the data of the first visit that enabled a definite diagnosis was considered.

Patients were inquired about dosage, weight, body height, smoking habits and renal or hepatic diseases.

The following parameters were compared:

- Age

- Sex

- Diagnosis of underlying disease

- Body weight

- Body mass index (= body weight $\left.[\mathrm{kg}] /(\text { body height }[\mathrm{m}])^{2}\right)$

- Daily dosage..

○ ..per body weight

- ..per ideal body weight (according to Broca)

- ideal weight for women $[\mathrm{kg}]=($ body height $[\mathrm{cm}]-1){ }^{*} 0.85$

- ideal weight for men $[\mathrm{kg}]=(\text { body height }[\mathrm{m}]-1)^{\star} 0.9$

- Duration of intake

- Total dosage..

$\circ \quad$..per body weight

- ..per ideal body weight (according to Broca)

- Nicotine abuse (ever vs. never)

- History of or ongoing reduction of excretory renal or liver function (present vs. absent)

- Sum of risk factors according to AAO (see introduction for list) with exception of accompanying retinal disease

The sum of risk factors according to AAO (see introduction for list, one point for fulfilment of each risk factor) was calculated for all patients on which information concerning the required parameters was available. High body fat level was defined as a BMl>25 kg/m $\mathrm{m}^{2}$. Accompanying retinal disease was discarded as patients with signs of retinal damage that was not definitely toxic were excluded from the analysis to ensure unequivocal diagnosis.

With exception of all dose related parameters analysis was conducted twice: 1. including all patients and 2. including only the chloroquine patients. Dose-related parameters were only compared in the chloroquine group. A separate analysis of hydroxychloroquine patients was not performed due to the small number of affected patients in this group.

The Mann-Whitney U-test was used for statistical comparison. P-values below 0.05 were regarded as statistically significant. 


\section{Results}

51 patients were included in the analysis. Due to uncertain diagnosis in spite of thourough examinations 9 patients with a history of hydroxychloroquine intake were excluded. Three patients were excluded due to the intake of both drugs which conflicted with the analysis in our setting. Finally, of the 28 patients taking hydroxychloroquine only 2 were affected by maculopathy while of the 23 chloroquine patients 16 had the disease.

In $31(61 \%)$ of 51 patients information on all above mentioned parameters could be acquired. In 20 patients information was incomplete. Nevertheless, information on age, sex, diagnosis, duration of intake, total dosage and daily dosage was complete in all included patients.

A summary of the results can be seen in the Table. 


\begin{tabular}{|c|c|c|c|c|c|c|c|c|c|c|c|}
\hline \multirow[t]{3}{*}{ SUBSAMPLE } & & \multirow{2}{*}{\multicolumn{2}{|c|}{$\frac{\text { ALL PATIENTS }}{\text { BOTH DRUGS }}$}} & \multicolumn{4}{|c|}{ ALL PATIENTS } & \multicolumn{4}{|c|}{ CHLOROQUINE } \\
\hline & & & & \multicolumn{2}{|c|}{ AFFECTED } & \multicolumn{2}{|c|}{ NOT AFF. } & \multicolumn{2}{|c|}{ AFFECTED } & \multicolumn{2}{|c|}{ NOT AFF. } \\
\hline & & & [\%] & & [\%] & & {$[\%]$} & & $\%$ & & [\%] \\
\hline \# PATIENTS & & 51 & & 18 & 35.3 & 33 & 64.7 & 16 & 31.4 & 7 & 13.7 \\
\hline \multirow[t]{2}{*}{ DRUG } & \# Hydroxychl. intake & 28 & 54.9 & 2 & 11.1 & 26 & 78.8 & & & 0 & \\
\hline & \# Chloroquine intake & 23 & 45.1 & 16 & 88.9 & 7 & 21.2 & 16 & 100.0 & 7 & 100.0 \\
\hline \multirow[t]{2}{*}{ AFFECTED yes/no } & \# Affected & 18 & 35.3 & 18 & 100.0 & & & 16 & 100.0 & & \\
\hline & \# Not affected & 33 & 64.7 & & & 33 & 100.0 & & & 7 & 100.0 \\
\hline \multirow[t]{2}{*}{ AGE } & Median Age [y] & 53.6 & & 61.3 & & 48.5 & & 61.7 & & 39.3 & \\
\hline & $\#$ Age $>60$ & 21 & 41.2 & 12 & 66.7 & 9 & 27.3 & 12 & 75.0 & 2 & 28.6 \\
\hline \multirow[t]{2}{*}{ SEX } & \# males & 5 & 9.8 & 0 & 0.0 & 5 & 15.2 & 0 & 0.0 & 1 & 14.3 \\
\hline & \# females & 46 & 90.2 & 18 & 100.0 & 28 & 84.8 & 16 & 100.0 & 6 & 85.7 \\
\hline \multirow[t]{2}{*}{ BODY WEIGHT } & Median body weight [kg] & 66.0 & & 65.0 & & 69.0 & & 65.0 & & 54.8 & \\
\hline & \# Body weight unknown & 18 & 35.3 & 7 & 38.9 & 11 & 33.3 & 7 & 43.8 & 1 & 14.3 \\
\hline \multirow[t]{3}{*}{ BMI } & Median BMI [kg/m2] & 23.9 & & 23.9 & & 23.9 & & 23.9 & & 18.7 & \\
\hline & \# BMI unknown & 19 & 37.3 & 8 & 44.4 & 11 & 33.3 & 8 & 50.0 & 1 & 14.3 \\
\hline & \# BMl>25 & 10 & 19.6 & 1 & 5.6 & 9 & 27.3 & 1 & 6.3 & 1 & 14.3 \\
\hline \multirow[t]{3}{*}{ DIAGNOSIS } & \# Rheumatoid Arthritis & 18 & 35.3 & 9 & 50.0 & 9 & 27.3 & 9 & 56.3 & 0 & 0.0 \\
\hline & \# Lupus & 14 & 27.5 & 4 & 22.2 & 10 & 30.3 & 3 & 18.8 & 3 & 42.9 \\
\hline & \# other & 19 & 37.3 & 5 & 27.8 & 14 & 42.4 & 4 & 25.0 & 4 & 57.1 \\
\hline \multirow[t]{2}{*}{ DURATION OF USE } & Median duration of use $[\mathrm{y}]$ & 4.0 & & 8.0 & & 3.0 & & 10.0 & & 5.5 & \\
\hline & \# Duration of use $>5$ years & 23 & 45.1 & 13 & 72.2 & 10 & 30.3 & 11 & 68.8 & 3 & 42.9 \\
\hline DAILY DOSAGE & Median daily dosage [mg] & & & & & & & 250.0 & & 250.0 & \\
\hline \multirow[t]{3}{*}{ DOSE/ BODY WEIGHT } & Median daily dose/ body weight $[\mathrm{mg} / \mathrm{kg}]$ & & & & & & & 3.79 & & 4.85 & \\
\hline & \# Daily dosage $>$ toxic threshold & 14 & 27.5 & 7 & 38.9 & 7 & 21.2 & 7 & 43.8 & 5 & 71.4 \\
\hline & \# Unknown & 19 & 37.3 & 7 & 38.9 & 12 & 36.4 & 7 & 43.8 & 2 & 28.6 \\
\hline \multirow[t]{3}{*}{ DOSE/ IDEAL WEIGHT } & Median daily dose/ ideal weight $[\mathrm{mg} / \mathrm{kg}]$ & & & & & & & 4.5 & & 4.2 & \\
\hline & \# Dose per ideal weight > threshold & 17 & 33.3 & 7 & 38.9 & 10 & 30.3 & 7 & 43.8 & 5 & 71.4 \\
\hline & \# Unknown & 20 & 39.2 & 8 & 44.4 & 12 & 36.4 & 8 & 50.0 & 2 & 28.6 \\
\hline TOTAL DOSE & Median total dose $[\mathrm{g}]$ & & & & & & & 604.5 & & 548.0 & \\
\hline \multirow[t]{3}{*}{ SMOKING } & \# Smoking y & 21 & 41.2 & 6 & 33.3 & 15 & 45.5 & 5 & 31.3 & 3 & 42.9 \\
\hline & \# Smoking $n$ & 9 & 17.6 & 5 & 27.8 & 4 & 12.1 & 4 & 25.0 & 2 & 28.6 \\
\hline & \# Unknown & 21 & 41.2 & 7 & 38.9 & 14 & 42.4 & 7 & 43.8 & 2 & 28.6 \\
\hline \multirow[t]{3}{*}{ LIVER DISEASE } & \# Liver disease y & 7 & 13.7 & 4 & 22.2 & 3 & 9.1 & 3 & 18.8 & 2 & 28.6 \\
\hline & \# Liver disease $n$ & 23 & 45.1 & 7 & 38.9 & 16 & 48.5 & 6 & 37.5 & 3 & 42.9 \\
\hline & \# Unknown & 21 & 41.2 & 7 & 38.9 & 14 & 42.4 & 7 & 43.8 & 2 & 28.6 \\
\hline \multirow[t]{3}{*}{ RENAL DISEASE } & \# Renal disease y & 5 & 9.8 & 3 & 16.7 & 2 & 6.1 & 1 & 6.3 & 0 & 0.0 \\
\hline & \# Renal disease $n$ & 25 & 49.0 & 8 & 44.4 & 17 & 51.5 & 8 & 50.0 & 5 & 71.4 \\
\hline & \# Unknown & 21 & 41.2 & 7 & 38.9 & 14 & 42.4 & 7 & 43.8 & 2 & 28.6 \\
\hline RISK FACTOR SUM & Mean Number of risk factors (AAO) & 1.9 & & 2.6 & & 1.6 & & 2.6 & & 2.2 & \\
\hline
\end{tabular}

Table: Summary of results 


\section{Sex}

5 males and 46 females were included in the study. No male was affected by the disease.

\section{Age}

Median age of all patients was 53.57 (17.64 to 84.23) years. Median age of affected patients was 61.25 (38.85 to 77.87) years and of not affected patients 48.5 (17.64 to $84.23)$ years. Age difference was statistically significant $(p=0.018)$. This significant difference also applied to the chloroquine subgroup ( $p=0.033$, Figure 1)

A Pearson analysis yielded no correlation between age and duration of intake or total dose respectively. This applied both to the entire sample $(p=0.063$ and 0.604$)$ as well as to the chloroquine subgroup ( $\mathrm{p}=0.288$ and 0.657 ).

\section{Diagnosis (underlying disease)}

The affected group suffered more frequently from rheumatoid arthritis compared to lupus erythematosus than the not affected group.

\section{Body weight and BMI}

Concerning the entire group median BMI was equal between affected and not affected patients and median body weight was even higher in the not affected patients. In the chloroquine subgroup both body weight and BMI of the not affected were lower than of the affected.

The two parameters did not exhibit significant differences between groups, neither in the complete sample $(p=0.866$ and 0.646 respectively) nor in the chloroquine subgroup ( $p=0.145$ and 0.142 respectively).

\section{Duration of intake}

Affected patients took the medication significantly longer than the not affected patients (8 [1.5 to 38 ] years vs. 3 [0.08 to 13.5 ] years, $p=0.002$, Figure 2). This applied only to the complete sample and not to the chloroquine subgroup (6.33 [1.5 to 38 ] years vs. 5.5 [3 to 13.5 ] years, $p=0.421$ ).

As could be expected, the Pearson analysis exhibited a highly significant correlation between total dose and duration of intake for the entire sample $(p<0.001)$ as well as for the chloroquine subgroup $(p=0.001)$.

\section{Smoking}

There were more patients with a history of or ongoing nicotine abuse in the not affected group (Figure 3). Differences were not statistically significant $(p=0.167$ [entire group] and 0.877 [chloroquine subgroup]).

\section{Liver and renal disease}

There were higher proportions of patients with a history of or present liver or kidney disease in the affected group (Figure 3). The differences did not reach a significant 
level neither in the entire sample nor in the chloroquine subgroup $(p=0.207$ and 0.81 for liver disease and $p=0.244$ and 0.456 for renal disease).

\section{Sum of AAO risk factors}

Affected patients had a significantly higher sum of risk-factors according to the AAO (Mean sum of risk factors $=2.6+/-0.97$ vs. $1.58+/-1.02, p=0.015$, Figure 4 ). The significance did not apply to the chloroquine subgroup $(\underline{2.63}+/-1.06$ vs. $\underline{2.2}+/-1.3$, $\mathrm{p}=0.497$ ).

\section{Dose-related parameters}

Due to the differing toxicity and pill weight $(250$ and $200 \mathrm{mg}$ ) of chloroquine and hydroxychloroquine all dose-related parameters were only analysed in the chloroquine subgroup. No separate analysis of the hydroxychloroquine subgroup was done as it would be hampered by the small amount of affected individuals.

The dose-related parameters showed no statistically significance in any case (Figure 5 and Figure 6). All parameters, except daily dose and daily dose per body weight were higher in the affected group.

- Total dose: $\underline{604.5}$ (274 to 1733 ) g vs. $\underline{548}$ (274 to 1231) g, p=0.612.

- Total dose per body weight: 10.22 (4.57 to 28.88$) \mathrm{g} / \mathrm{kg}$ vs. $\underline{9.45}$ (5.67 to 23.9) $\mathrm{g} / \mathrm{kg}, \mathrm{p}=0.549$

- $\quad$ Total dose per ideal weight: $\underline{12.18}$ (5.76 to 34.56$) \mathrm{g} / \mathrm{kg}$ vs. $\underline{8.27}$ (5.46 to 20.69) $\mathrm{g} / \mathrm{kg}, \mathrm{p}=0.661$

- Daily dose: $\underline{250}$ (125 to 750 ) mg vs. $250 \mathrm{mg}, \underline{\mathrm{p}=0.328}$

- Daily dose per body weight: $\underline{3.79}$ (2.08 to 12.93$) \mathrm{mg} / \mathrm{kg}$ vs. $\underline{4.85}$ (3.57 to 5.56 ) $\mathrm{mg} / \mathrm{kg}, \mathrm{p}=0.317$

- Daily dose per ideal weight: $\underline{4.53}$ (2.49 to 14.96$) \mathrm{mg} / \mathrm{kg}$ vs. $\underline{4.2}$ (3.77 to 4.99$)$ $\mathrm{mg} / \mathrm{kg}, \mathrm{p}=0.124$

Of the affected chloroquine patients $43.7 \%$ took daily doses above the risk threshold of $3 \mathrm{mg} / \mathrm{kg}$ body weight, $12.5 \%$ lay below the threshold, subsumption of $43.8 \%$ was impossible due to missing body weight and height data.

Of the not affected chloroquine patients $71 \%$ were overdosed, non lay below the threshold while in $29 \%$ missing body dimensions precluded dose calculation.

The data on daily dose per ideal weight was very much comparable.

Speaking of hydroxychloroquine: Two of our 28 patients recieved a daily dose above the risk level of $6.5 \mathrm{mg} / \mathrm{kg} / \mathrm{d}$ and both patients were unaffected. Relating dosage to the ideal weight, 5 of 28 patients were above the cut off yet all of them being unaffected. The affected patients all received doses below the risk level.

\section{Discussion}

\section{Problem of establishing a definite diagnosis}

The first issue encountered in this analysis is the difficulty of establishing a definite diagnosis. Since the toxic effect of both drugs may outlast their cessation early diagnosis of maculopathy is essential. ${ }^{5 ; 6}$ On the other hand, when trying to catch the 
first sign of retinal damage overdiagnosis impends with the risk of discontinuating a drug that is safely and effectively controlling the underlying disease. ${ }^{7}$

While all chloroquine patients could be included in this analysis 9 hydroxychloroquine patients had to be excluded whose borderline findings made an unequivocal classification impossible. Despite thorough and repeated examination and the above mentioned classification scheme a secure diagnosis of maculopathy was possible in only 2 of originally 37 hydroxychloroquine patients. Some of the excluded patients had maculopathy that was impossible to discern from ARM. Others had isolated mfERG changes without any further sign of retinal damage. This confirms the concern of Marmor: While the mfERG basically allows earlier diagnosis of functional retinal alterations care has to be taken to not exclusively rely on the mfERG. ${ }^{8}$ Isolated mfERG changes occuring under therapy with either drug may be reversible and not necessarily imply maculopathy. ${ }^{9}$

Maybe the additional employment of fundus autofluorescence imaging or high resolution optical coherence tomography could have enabled a definite diagnosis in some of the excluded patients but we did not dispose of either device. ${ }^{10-12}$

\section{Sex}

The fact that no male patient suffered from toxic retinal damage owes to the epidemiology of autoimmune diseases which predominantly affect women and consequently to the sex distribution in our sample. We cannot conclude if female sex is a risk factor for retinal damage due to (hydroxy-) chloroquine.

\section{Age}

Affected patients were significantly older than not affected patients. The Pearson analysis ruled out a relation between age and duration of intake or total dose so that advanced age itself can be regarded as an independent risk factor for developing toxic retinal damage.

\section{Diagnosis of underlying disease}

The ratio of rheumatoid arthritis to lupus erythematosus was higher in the affected patients. We could not confirm earlier reports that allocated a higher risk of retinal damage to lupus patients. ${ }^{13}$

\section{Body weight and BMI}

No significant difference applied to either parameter. Only in the chloroquine subgroup body weight and BMI of the affected individuals expectedly lay above the not affected individuals. In clinical practice of course only BMI should be considered as it reflects the relation of body weight to body height.

\section{Duration of intake}

Statistical analysis proved that the duration of drug intake is a relevant risk factor. Pearson analysis especially showed that in spite of a high correlation between duration of intake and total dosage, the former can be regarded as an independent risk factor. 


\section{Smoking, liver and renal disease}

It would not primarily be expected that nicotine abuse was more frequent in the not affected individuals especially when epidemiological studies on ARM proved smoking as an independent risk factor. ${ }^{14-16}$ Analysis of larger patient groups are necessary to clarify this issue.

As expected, affected patients suffered more frequently from liver and renal diseases. Although the differences lacked statistical significance both factors should be taken into account when deciding on screening intervals.

\section{Sum of AAO risk factors}

The combination of AAO risk factors gives an estimate of the individual risk profile even though we disregarded accompanying retinal diseases. For exact discrimination between affected and not affected individuals, patients showing signs of retinal disease that was not clearly of toxic origin were excluded from the analysis. Nevertheless this important factor should be considered in clinical practice.

The cut off for "high body fat level" was set at a BMI of 25 as it marks the limit of normal weight. Only 3 patients had a BMI above 30 (obesity), two being not affected hydroxychloroquine patients and one being an affected chloroquine patient.

Only two individuals exhibited no risk factor at all, both taking hydroxychloroquine. According to the $A A O$, this would mean annual examinations for the vast majority of our patients.

\section{Dose-related parameters}

Total dose

Affected patients had taken a insignificantly higher total dose of chloroquine as well as a higher total dose in relation to ideal weight than not affected patients. In most publications total dose is not assumed to be a relevant risk factor. ${ }^{17-20}$ Nevertheless, our analysis suggests to be aware of the cumulative dose when following up for retinal toxicity.

\section{Daily dose}

It is striking that the majority of our chloroquine patients - affected as well as not affected - took daily doses above the risk threshold. Few practicioners seem to be aware of this threshold when prescribing the drug. On the other hand the clinical relevance of this strict threshold recommendation is challenged as most of the not affected patients also took doses above the cut off. In case of hydroxychloroquine, few patients exceeded the risk threshold and none of them suffered from maculopathy.

Our dosage findings confirm that the relation to ideal weight is essential. But even then the definition of a realistic and relevant threshold remains difficult.

\section{Sources of imprecision}

The following factors may be sources of imprecision:

- The relatively small sample size, especially the low number of affected patients in the hydroxychloroquine group. 
- The fraction of patients with incomplete data.

- Having been collected retrospectively, relevant data - especially body weight and dosage - is prone to recall bias.

- Smoking habits and accompanying renal or liver diseases are difficult to quantify. The retrospective nature of this study limited the differentiation on never vs. ever and present vs. absent.

- Regarding daily dosage, we accounted for the highest dosage ever taken over a period instead of calculating the mean daily dose. By doing so we might have overemphasized short periods of high daily doses over long periods with lower dosing.

- Referral bias: Most patients of our department were referred by ophthalmologists who previously suspected retinal damage. This especially leads to distortion of incidence data.

\section{Conclusion}

As expected, most of the analysed risk factors - with exception of smoking, daily dose and daily dose per body weight - were elevated in the affected individuals. Age and duration of intake can be regarded as major risk factors. The toxic threshold for daily chloroquine dose was exceeded by most patients emphasizing the need of individual weight-adjusted dosing. We could not confirm that lupus patients are at higher risk of developing maculopathy. Smoking history is probably negligible. The combination of risk-factors as postulated by the AAO turned out to be a good estimation of the individual risk profile.

According to the $A A O$, the existence even of a single risk factor implies annual examinations. Only two of our patients exhibited no risk factor at all and we suppose that a similar relation applies to the entirety of chloroquine and hydroxychloroquine patients. Furthermore, while we could confirm the importance of most risk factors, there also are affected patients with low risk profiles (Figure 4) and especially short duration of use (Figure 2). Bearing in mind that early stage maculopathy may develop unperceived by the patient, only annual screening for all patients from the very beginning of therapy ensures a timely diagnosis of toxic retinal damage.

The question remains if there are relevant risk factors that have been missed so far. The focus of attention already turned on genetics: Missense mutations of the ABCA4 gene were reported to be more frequent in patients than in controls. ${ }^{22}$ Further research will show if other genes play substantial roles in toxic retinal damage.

\section{Licence for Publication}

The Corresponding Author has the right to grant on behalf of all authors and does grant on behalf of all authors, an exclusive licence (or non exclusive for government employees) on a worldwide basis to the BMJ Publishing Group Ltd to permit this article (if accepted) to be published in BJO and any other BMJPGL products and sublicences such use and exploit all subsidiary rights, as set out in our licence (http://group.bmj.com/products/journals/instructionsfor-authors/licence-forms). 


\section{Competing Interest}

Competing Interest: None declared. 


\section{Reference List}

1. Yam JC, Kwok AK. Ocular toxicity of hydroxychloroquine. Hong.Kong.Med.J. 2006;12:294-304.

2. Marmor MF, Carr RE, Easterbrook M, Farjo AA, Mieler WF. Recommendations on screening for chloroquine and hydroxychloroquine retinopathy: a report by the American Academy of Ophthalmology. Ophthalmology 2002;109:1377-82.

3. Johnson MW, Vine AK. Hydroxychloroquine therapy in massive total doses without retinal toxicity. Am.J.Ophthalmol. 1987;104:139-44.

4. Ruther K, Foerster J, Berndt S, Schroeter J. [Chloroquine/hydroxychloroquine: variability of retinotoxic cumulative doses]. Ophthalmologe 2007;104:875-9.

5. Browning DJ. Hydroxychloroquine and chloroquine retinopathy: screening for drug toxicity. Am.J.Ophthalmol. 2002;133:649-56.

6. Easterbrook M. Current concepts in monitoring patients on antimalarials. Aust.N.Z.J.Ophthalmol. 1998;26:101-3.

7. Levy GD, Munz SJ, Paschal J, Cohen HB, Pince KJ, Peterson T. Incidence of hydroxychloroquine retinopathy in 1,207 patients in a large multicenter outpatient practice. Arthritis Rheum. 1997;40:1482-6.

8. Marmor MF. The dilemma of hydroxychloroquine screening: new information from the multifocal ERG. Am.J.Ophthalmol. 2005;140:894-5. 
9. Lai TY, Chan WM, Li H, Lai RY, Lam DS. Multifocal electroretinographic changes in patients receiving hydroxychloroquine therapy. Am.J.Ophthalmol. 2005;140:794-807.

10. Kellner $U$, Renner $A B$, Tillack $H$. Fundus autofluorescence and mfERG for early detection of retinal alterations in patients using chloroquine/hydroxychloroquine. Invest Ophthalmol. Vis.Sci. 2006;47:3531-8.

11. Kellner S, Weinitz S, Kellner U. Spectral domain optical coherence tomography detects early stages of chloroquine retinopathy similar to multifocal electroretinography, fundus autofluorescence and near-infrared autofluorescence. Br.J.Ophthalmol. 2009; 93:1444-1447 doi:10.1136/bjo.2008.157198 [published Online First: 18 August 2009].

12. Pasadhika S, Fishman GA. Effects of chronic exposure to hydroxychloroquine or chloroquine on inner retinal structures. Eye 2009; 24:340-346 doi:10.1038/eye.2009.65 [published Online First: 17 April 2009].

13. Voipio H. Incidence of chloroquine retinopathy. Acta Ophthalmol.(Copenh) 1966;44:349-54.

14. Swaroop A, Chew EY, Bowes RC, Abecasis GR. Unraveling a Multifactorial Late-Onset Disease: From Genetic Susceptibility to Disease Mechanisms for Age-Related Macular Degeneration. Annu.Rev.Genomics Hum.Genet. 2009; 10:19-43 doi:10.1146/annurev.genom.9.081307.164350 [published Online First; 28 April 2009]. 
15. Risk factors associated with age-related macular degeneration. A case-control study in the age-related eye disease study: Age-Related Eye Disease Study Report Number 3. Ophthalmology 2000;107:2224-32.

16. Vingerling JR, Hofman A, Grobbee DE, de Jong PT. Age-related macular degeneration and smoking. The Rotterdam Study. Arch.Ophthalmol. 1996;114:1193-6.

17. Ruther K, Foerster J, Berndt S, Schroeter J. [Chloroquine/hydroxychloroquine: variability of retinotoxic cumulative doses]. Ophthalmologe 2007;104:875-9.

18. Araiza-Casillas R, Cardenas F, Morales $\mathrm{Y}$, Cardiel MH. Factors associated with chloroquine-induced retinopathy in rheumatic diseases. Lupus 2004;13:119-24.

19. Rynes RI, Krohel G, Falbo A, Reinecke RD, Wolfe B, Bartholomew LE. Ophthalmologic safety of long-term hydroxychloroquine treatment. Arthritis Rheum. 1979;22:832-6.

20. Tobin DR, Krohel G, Rynes RI. Hydroxychloroquine. Seven-year experience. Arch.Ophthalmol. 1982;100:81-3.

21. Bernstein HN. Ophthalmologic considerations and testing in patients receiving long-term antimalarial therapy. Am.J.Med. 1983;75:25-34.

22. Shroyer NF, Lewis RA, Lupski JR. Analysis of the ABCR (ABCA4) gene in 4aminoquinoline retinopathy: is retinal toxicity by chloroquine and hydroxychloroquine related to Stargardt disease? Am.J.Ophthalmol. 2001;131:761-6. 
Figures

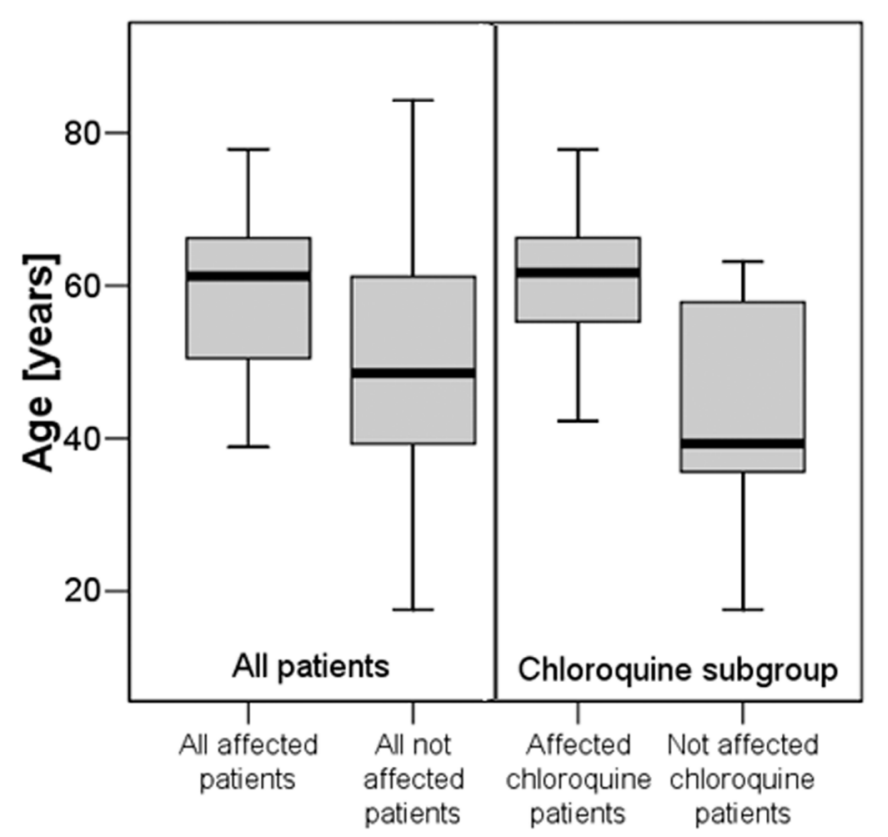

Figure 1: Boxplots showing the comparison of age between affected and not affected individuals. 


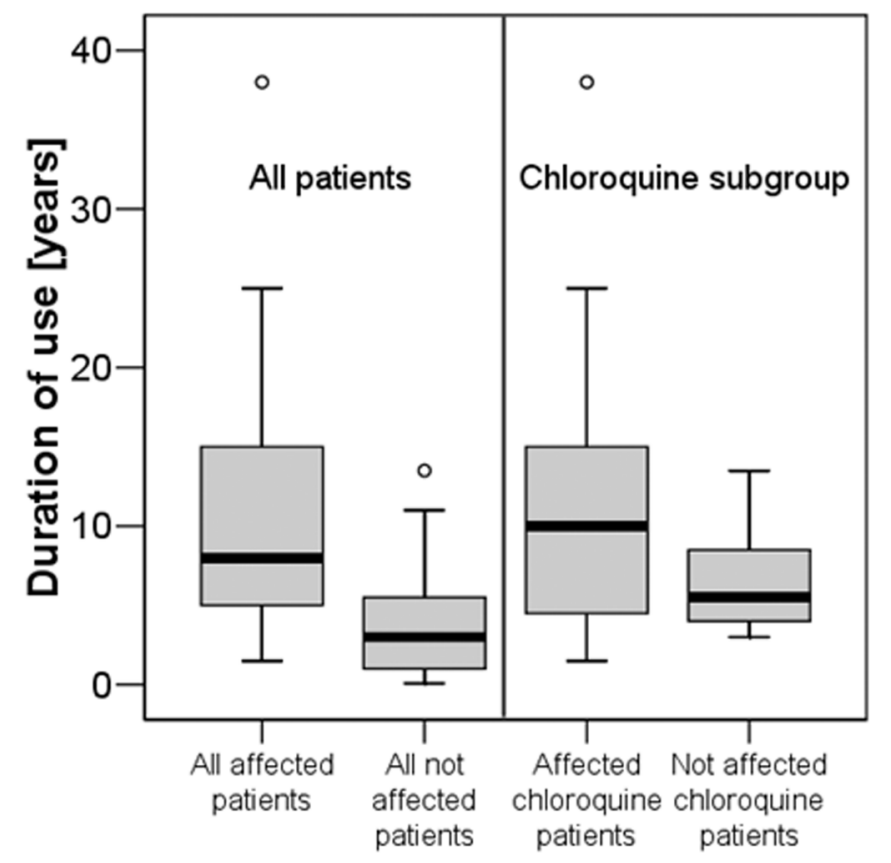

Figure 2: Boxplots showing the duration of use compared between affected and not affected individuals. 


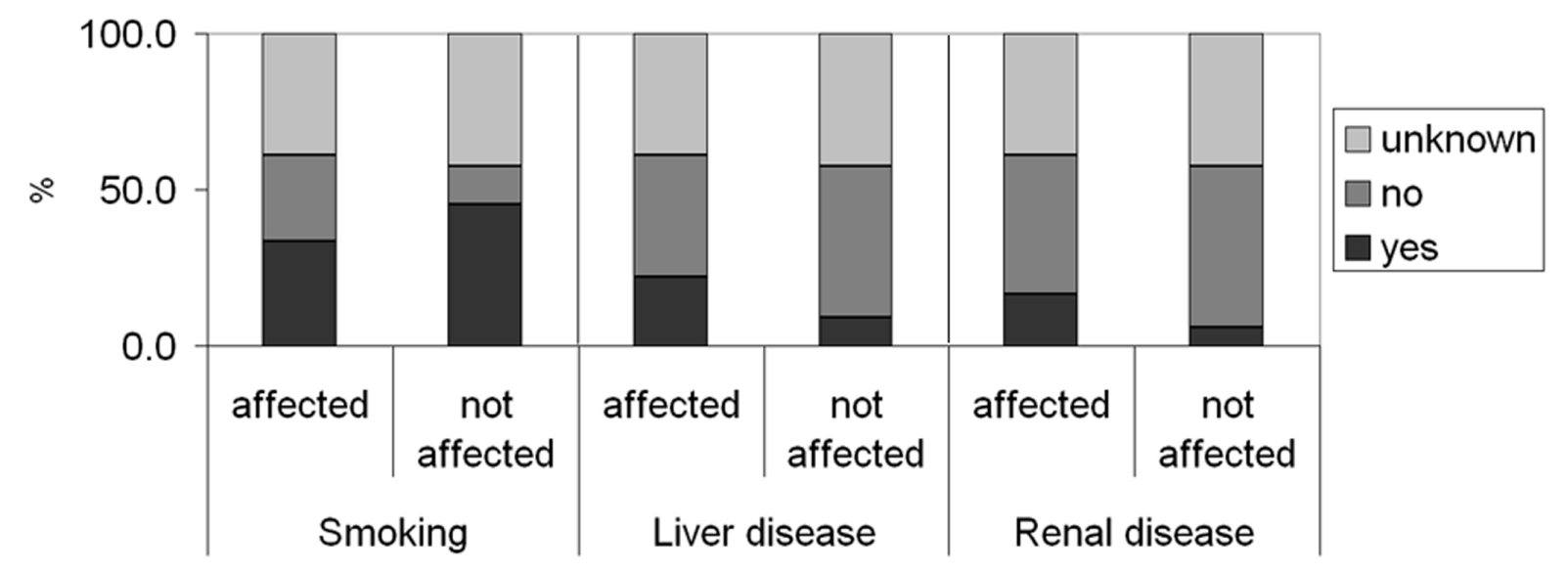

Figure 3: Comparison between nicotine abuse, liver disease and renal disease between affected and not affected individuals. 


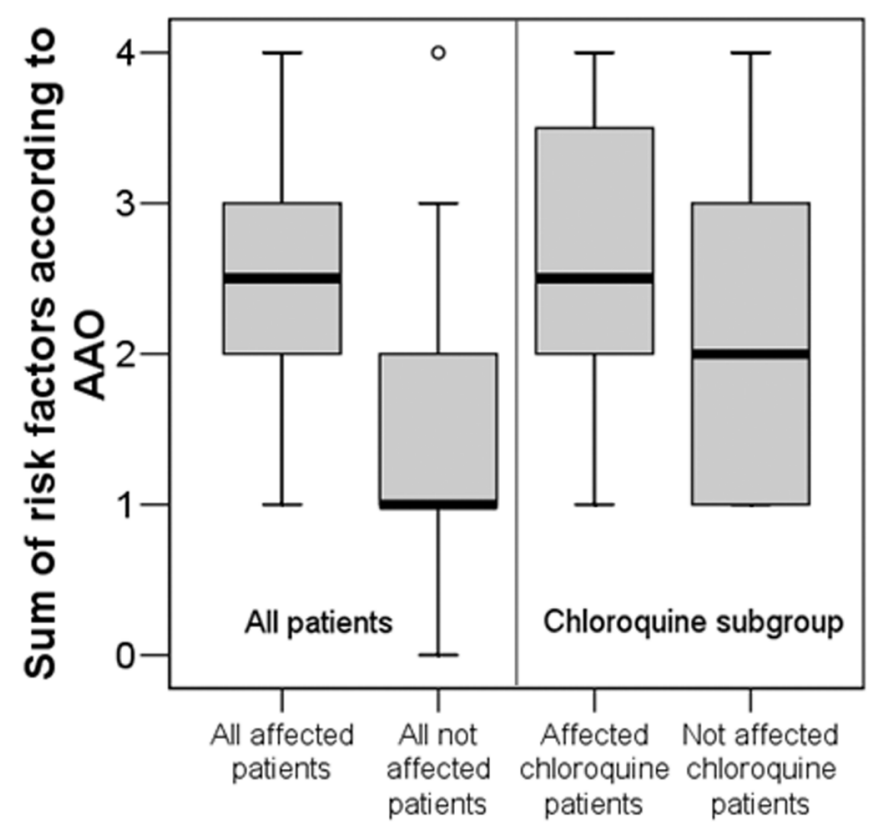

Figure 4: Boxplots showing the sum of risk factors according to the AAO compared between affected and not affected patients. 

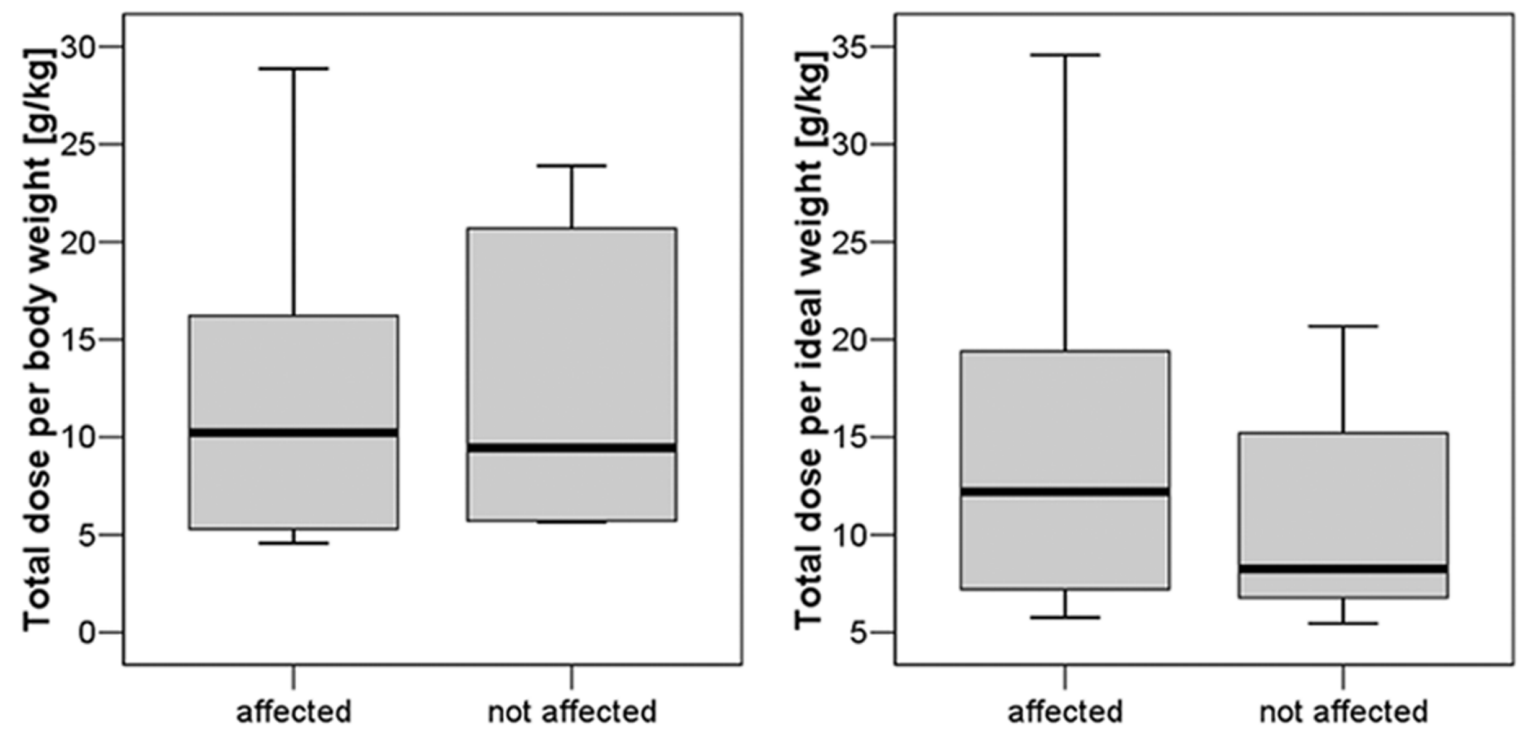

Figure 5: Boxplots showing the comparison of total dose per body weight and total dose per ideal weight between affected and not affected chloroquine patients. Dosage of affected patients lay above the not affected patients only when related to ideal weight. 

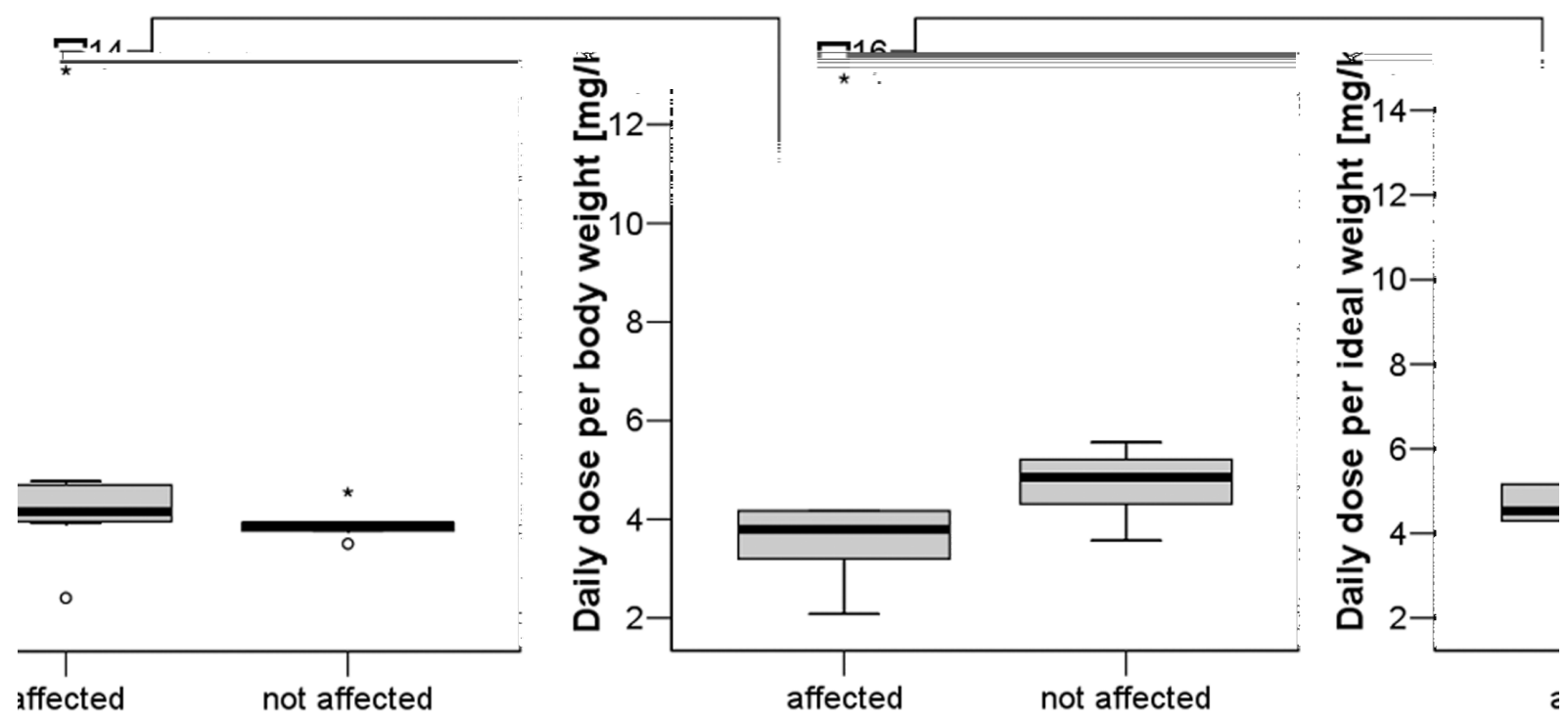

Figure 6: Boxplots showing the comparison of daily dose per body weight and daily dose per ideal weight between affected and not affected chloroquine patients. Again, dosage of affected patients lay above the not affected patients only when related to ideal weight. 